\section{Serum sodium/potassium ratio in patients with rheumatoid arthritis and osteoarthritis}

\author{
Alexander P. Rozin, ${ }^{1}$ \\ Josef Pruzansky, ${ }^{2}$ Yeouda Edoute, ${ }^{3}$ \\ Alexandra Balbir-Gurman' \\ 'B. Shine Department of Rheumatology; \\ ${ }^{2}$ Department of Preventive Medicine, \\ Rambam Health Care Campus and \\ Technion; \\ ${ }^{3}$ Clinical Department of Venus \\ Technologies, Haifa, Israel
}

\section{Abstract}

Rheumatoid arthritis (RA) and osteoarthritis (OA) may cause rapid joint destruction and chronic disability. The main pathological feature of RA is chronic synovitis, resulting in bone resorption due to TNF- $\alpha$-RANKL-DKK-1 mechanism. The main pathological feature of $\mathrm{OA}$ is increased osteophyte formation governed by members of the TGF/BMP protein family, as well as by the group of Wingless (Wnt) proteins. The renin-angiotensin-adosterone system has been identified as an important regulator of fibrosis and is being investigated as a potential target for antifibrotic drugs. Experimental evidence also indicates that aldosterone directly contributes to accelerate damage by sustaining cell growth, inflammation and fibrosis reactions. This occurs through production of growth factors including TGF- $\beta$. The objective of this study was to investigate serum sodium/potassium ratio (SSPR) as an indicator of aldosterone function in patients with $\mathrm{OA}$ and RA. Retrospective analysis of SSPR of patients aged 40-70 with active $R A$ ( $n=50$ patients) and OA $(n=30)$ was performed as of medical records from the in-patient clinic. These findings were compared with the data of SSPR of healthy controls $(n=30)$. SSPR of patients with RA, OA and healthy controls was within the recognized normal range (27-40). The lowest SSPR was found in healthy controls: $30.9 \pm 2.4$. Significantly higher values were found in the RA group $(32.9 \pm 2.9 ; \mathrm{P}<0.001)$ and $\mathrm{OA}$ patients $(34.3 \pm 2.1 ; \mathrm{P}<0.001)$. The SSPR was significantly higher in the $\mathrm{OA}$ group compared to RA $(\mathrm{P}=0.004)$. No correlation was observed between SSPR and age $(\mathrm{P}=0.534)$. We conclude that patients with $\mathrm{OA}$ had relatively increased SSPR, indirectly indicating increased aldosterone function compared with controls and patients with RA.

\section{Introduction}

Rheumatoid arthritis (RA) is a chronic systemic autoimmune disorder that affects $1 \%$ of the adult population which, if not treated, causes rapid loss of joint function. RA occurs worldwide, striking three times more females than males. Although it can occur at any age, it begins most often between the ages of 25 and 55 years. The main pathological feature of rheumatoid arthritis (RA) is chronic inflammation of the synovial membrane (synovitis) which may become erosive and extend to cartilage and bone and cause bone resorption via the TNF- $\alpha$-RANKL-DKK-1 mechanism. ${ }^{1-3}$ Osteoarthritis (OA, also known as degenerative arthritis, degenerative joint disease), is a clinical syndrome in which low-grade inflammation and abnormal wearing of the cartilage results in cartilage damage, osteophyte formation, bone, and soft tissue damage and pain in the joints, affecting lubricating properties of the synovial fluid. $\mathrm{OA}$ is the most common form of arthritis. It may rapidly cause joint destruction and is the leading cause of chronic disability. $\mathrm{OA}$ affects nearly $7 \%$ of the population and accounts for $25 \%$ of visits to primary care physicians and half of all NSAID (Non-Steroidal AntiInflammatory Drugs) prescriptions. It is estimated that $80 \%$ of the population will have radiographic evidence of $\mathrm{OA}$ by the age of 65 , although only $60 \%$ of them will be symptomatic. In the United States, hospitalizations for osteoarthritis soared from approximately 322,000 in 1993 to 735,000 in 2006 . The main pathological feature of osteoarthritis (OA) is increased bone (osteophyte) formation. This is governed by members of the TGF/BMP protein family, as well as by the group of Wingless (Wnt) proteins. Wnt proteins seem to be regulators of osteophyte formation. Binding of Wnt to its receptor Lrp5/6 and activation of downstream regulators such as $\beta$-catenin are crucial steps for bone formation. ${ }^{4}$ Wnt activation also blocks osteoclast differentiation through increased production of osteoprotegerin. ${ }^{5} \mathrm{~A}$ functional relationship between Wnt-induced secreted protein-1 (WISP-1) and TGF- $\beta$ as modulators of proliferation and osteogenic differentiation has recently been found. ${ }^{6}$ WISP-1 may be a novel regulator of TGF- $\beta 1$ signaling in osteoblast-like cells. The renin-angiotensinadosterone system has been identified as an important regulator of fibrosis and is being investigated as a potential target of antifibrotic drugs. Experimental evidence also indicates that aldosterone, besides being a regulator of extracellular fluid volume and sodium and potassium balance, directly contributes to accelerate damage by sustaining cell growth, inflammation and fibrosis. This occurs through the production of growth factors including TGF$\beta .{ }^{7}$ We retrospectively investigated serum sodi-
Correspondence: Dr. Alexander Rozin, Department of Rheumatology, Rambam Health Care Campus, POB 9602, Haifa 31096, Israel

E-mail: a_rozin@rambam.health.gov.il

Key words: sodium, potassium, rheumatoid arthritis, osteoarthritis, sodium/potassium ratio, aldosterone.

Conflict of interests: none declared.

Funds: None.

Received for publication: 28 March 2010.

Revision received: 29 June 2010.

Accepted for publication: 29 June 2010.

This work is licensed under a Creative Commons Attribution 3.0 License (by-nc 3.0).

(C) Copyright Rozin A.P. et al., 2010

Licensee PAGEPress, Italy

Rheumatology Reports 2010; 2:e5

doi:10.4081/rr.2010.e5

um/potassium ratio (SSPR) as an indicator of aldosterone function in patients with $\mathrm{OA}$ where the osteofibrotic process is predominant, as compared to patients with RA in whom fibrosis is inhibited. Aldosterone, a hormone produced and secreted by the adrenal glands, signals the kidneys to excrete less sodium and more potassium. That is the reason SSPR was used for assessment of hyper- and hypoaldosteronism as a part of SUSPUP hyperaldosteronism assessment. ${ }^{8}$ Normal SSPR was investigated in healthy controls and was found to be $33.4 \pm 1.82 .^{9}$

\section{Materials and Methods}

We undertook a retrospective collection of serum sodium/potassium (QuikLYTER, DADE BEHRING) ratio data of 50 patients with RA, 30 patients with $\mathrm{OA}$ and 30 healthy controls from medical documentation of rheumatology and preventive medicine departments at Rambam Health Care Campus, which provides health care for the Northern-Israel region. Data of the three groups were compared. QuikLYTE test detects an electrical potential proportional to each specific ion. The study was approved by an institutional review board. The subjects gave informed consent.

\section{Study population}

Included in the study were patients aged 4075 years with low-moderately active RA (DAS 28:3-5) who fulfilled the 1987 revised ARA cri- 
teria for RA and patients aged 40-75 years with OA, who fulfilled the 1986 ARA criteria for idiopathic OA of the knee, and/or the 1990 ACR criteria for OA of the hand, and/or the 1991 ACR criteria for OA of the HIP and VAS score of pain of $30-80 \mathrm{~mm}$.

Exclusion criteria included: i) patients taking medications which alter electrolyte metabolism and water balance: e.g. diuretics, ACE inhibitors, ATII receptor blockers, spironolactones, corticosteroids, K-supplements, $\beta$-agonists; ii) patients with acute and chronic diseases which alter electrolyte balance: e.g. renal failure, heart failure, liver cirrhosis, arterial hypertension (secondary hyperaldosteronism), diabetes mellitus (secondary hypoaldosteronism), and other endocrine disorders; iii) patients suffering from acute exacerbation of RA or OA, in order to exclude the

Table 1. Summary patient data: age, disease duration and $\mathrm{Na} / \mathrm{K}$ ratio according to control (0), RA (1) and OA (2) groups.

\begin{tabular}{|c|c|c|c|}
\hline GR & & Age & NA/K \\
\hline \multicolumn{4}{|l|}{0} \\
\hline & Sum & 1532 & 923.5 \\
\hline & Mean & 51.07 & 30.783 \\
\hline & $\mathrm{N}$ & 30 & 30 \\
\hline & Std. Deviation & 8.136 & 2.4426 \\
\hline & Median & 51.00 & 30.450 \\
\hline & Minimum & 41 & 26.9 \\
\hline & Maximum & 79 & 36.3 \\
\hline \multicolumn{4}{|l|}{1} \\
\hline & Sum & 2826 & 1645.6 \\
\hline & Mean & 56.52 & 32.912 \\
\hline & $\mathrm{N}$ & 50 & 50 \\
\hline & Std. Deviation & 16.749 & 1.9445 \\
\hline & Median & 60.00 & 32.800 \\
\hline & Minimum & 19 & 28.1 \\
\hline & Maximum & 90 & 37.9 \\
\hline \multicolumn{4}{|c|}{ 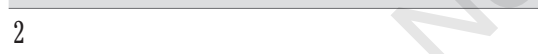 } \\
\hline & Sum & 1933 & 1029.9 \\
\hline & Mean & 64.43 & 34.330 \\
\hline & $\mathrm{N}$ & 30 & 30 \\
\hline & Std. Deviation & 11.494 & 2.0573 \\
\hline & Median & 63.00 & 34.350 \\
\hline & Minimum & 39 & 30.4 \\
\hline & Maximum & 89 & 38.6 \\
\hline \multicolumn{4}{|c|}{ Total } \\
\hline & Sum & 6291 & 3599.0 \\
\hline & Mean & 57.19 & 32.718 \\
\hline & $\mathrm{N}$ & 110 & 110 \\
\hline & Std. Deviation & 14.277 & 2.4851 \\
\hline & Median & 58.50 & 32.800 \\
\hline & Minimum & 19 & 26.9 \\
\hline & Maximum & 90 & 38.6 \\
\hline
\end{tabular}

a. Grouping Variable: GR influence of stress syndromes: e.g. SIADH syndrome (syndrome of inappropriate antidiuretic hormone secretion) and syndrome of adrenal insufficiency.

\section{Statistical analysis}

Data were analyzed using SPSS 12.0 software. Comparison between continuous variables of SSPR was made with the MannWhitney U non-parametric test. For group comparison of age variables a two-tailed Student's t-test was used. Spearman's non-parametric correlation was performed in order to examine relationships between age and $\mathrm{Na} / \mathrm{K}$ ratio. $\mathrm{P}$ values of 0.05 or less were considered statistically significant.

\section{Results}

SSPR of patients with RA, OA as well as healthy controls (Table 1) was investigated and its value was found within the normal range according to literature data: $27-40 .^{9}$ The lowest SSPR was found in healthy controls: $30.9 \pm 2.4$. Significantly higher values were found in the RA group $(32.9 \pm 2.9 ; \mathrm{P}<0.001)$ and 0 A patients $(34.3 \pm 2.1 ; \mathrm{P}<0.001)$. The SSPR was significantly higher in the OA group compared to RA ( $\mathrm{P}=0.004)$ (Table 2). No correlation was observed between SSPR and age for ally subjects investigated $(\mathrm{P}=0.534)$, for controls $(\mathrm{P}=0.223)$, and for $\mathrm{OA}$ group $(\mathrm{P}=0.915)$. Negative mild statistical significant correlation was obtained for RA patients $(\mathrm{P}=0.03)$ (Table 3 ). The group of RA (age $56.5 \pm 16.8$ years) was older than controls (age $51.1 \pm 8.1$ years) $(\mathrm{P}=0.055)$ and $\mathrm{OA}$ patients (age
$64.4 \pm 11.5$ years) were older than the RA group $(\mathrm{P}=0.015)$. But no total correlation was observed between SSPR and age. The investigated groups were adjusted for age and showed similar statistically significant SSPR differences: $0-1$ groups $\mathrm{P}<0.001,0-2$ groups $\mathrm{P}<0.001$. No difference was observed between OA and RA: $1-2$ groups $\mathrm{P}=0.3$.

\section{Discussion}

Sodium/potassium ratio as an indicator of aldosteron function (sodium increase and potassium decrease) was investigated in RA and $\mathrm{OA}$ patients compared with healthy controls. We found normal but sustained increasing values of SSPR in the range of healthy RAOA. From a clinical point of view, aldosteronerenin ratio determination is time consuming, expensive, and the information provided is often limited. ${ }^{8}$ We, therefore, suggest an inexpensive parameter that is easy and quick to determine and provides rapid information on an individual's mineralocorticoid activity in an outpatient setting. Stress due to severe disabling disease such as RA causes hyperactivation of the renin-angiotensin-aldosteron system. ${ }^{10}$ This was observed in our RA series with higher SSPR values compared to controls. Furthermore, direct activation of proinflammatory cytokines by aldosterone may be implicated in the pathogenesis of RA inflammation and its inhibition may have therapeutic significance. $^{11}$

OA is known as an age-related disease. The effects of aging on chondrocytes and their matrix result in a tissue that is less able to maintain homeostasis when stressed, resulting in breakdown and loss of the articular cartilage. Articular chondrocytes exhibit an age-

Table 2. The $\mathrm{Na} / \mathrm{K}$ ratio and age data of comparision between control (0) and $\mathrm{RA}(1)$, control (0) and OA (2), and RA (1) and OA (2) group.

\begin{tabular}{lccccc}
$\begin{array}{l}\text { t-test } \\
\text { (age) P }\end{array}$ & $\begin{array}{c}\text { Asymp. Sig. } \\
\text { (two-tailed) P } \\
\text { (Na/K ratio) }\end{array}$ & Z (Na/K ratio) & $\begin{array}{c}\text { Wilcoxon W } \\
\text { (Na/K ratio) }\end{array}$ & $\begin{array}{c}\text { Mann-Whitney U } \\
\text { (Na/K ratio) }\end{array}$ & $\begin{array}{c}\text { Test } \\
\text { Groups }\end{array}$ \\
0.055 & $<0.001$ & -3.728 & 840.000 & 375.000 & $0-1$ \\
$<0.001$ & $0.001>$ & -4.895 & 584.000 & 119.000 & $0-2$ \\
\hline 0.015 & 0.004 & -2.874 & 1736.000 & 461.000 & $1-2$ \\
\hline
\end{tabular}

Table 3. Spearman's non-parametric correlation between age and $\mathrm{Na} / \mathrm{K}$ ratio for total and different groups: controls (0), RA (1), OA (2).

\begin{tabular}{lcccc} 
Total & OA (2) & RA (1) & Controls (0) & Group \\
110 & 30 & 50 & 30 & N of patients \\
0.060 & -0.020 & -0.307 & 0.223 & Correlation coefficient \\
\hline 0.534 (NS) & $0.915(\mathrm{NS})$ & 0.030 & $0.223(\mathrm{NS})$ & Sig. (two-tailed) P \\
\hline NS - not significant & & & &
\end{tabular}


related decline in proliferative and synthetic capacity while maintaining the ability to produce pro-inflammatory mediators and matrix degrading enzymes. These findings are most likely a consequence of extrinsic stressinduced senescence driven by oxidative stress rather than intrinsic replicative senescence. ${ }^{12}$ We observed suprisingly higher SSPR values in the older OA group indicating increased aldosterone function. But this was found for the total OA group, which was older than RA patients. After age and disease duration adjustment, we did not find any differences. In contrast, the RA group showed negative correlation between aldosterone function and age, which may reflect an exhaustion of the mineraloctorticoid mechanism in elderly RA patients. Whether aldosterone may be involved in osteophyte formation and OA development and progression should be dealt with in further trials. However, we observed statistically significant increased aldosterone function in the OA population.

In addition to the impact of aldosterone on ostheophyte formation by induction of TGF- $\beta,{ }^{6}$ another influence of aldosterone on joints has been described. Cartilage degradation is a characteristic feature of various types of human arthritis, notably RA and OA. The influence of glucocorticoid and other steroid hormones on cartilage proteoglycan breakdown was examined in a model system in which breakdown is readily quantified by the release of proteoglycan from cultured bovine nasal cartilage discs. ${ }^{13}$ Endotoxin (bacterial lypopolysaccharide) treatment enhanced the depletion of cartilage proteoglycan by 2-3 fold. This was inhibited in a concentration-dependent manner by hydrocortisone and other glucocorticoid hormones. Other C-21 steroid hormones (progesterone and aldosterone) were also inhibitory. Cleavage of endotoxin-treated cartilage with proteoglycan product formation of smaller average molecular weight (sepharose) was unaffected by $\beta$-estradiol, and was partially blocked by aldosterone and largely prevented by hydrocortisone administration. ${ }^{13}$ Aldosterone as a part of hypothalmic-adrenal axis might be considered a protective factor for prevention of instability of impaired joints (osteophytes) and may delay cartilage loss (proteoglycan breakdown inhibition).

All our patients and controls were devoted to the Mediterranean diet, including regular consumption of vegetables, fruit, olive oil, fish 2-3 times per week and poultry 3-4 times per week. We believe all patients had similar sodium and potassium levels in their diet.

The data were surprising in that there was a relatively narrow range of SSPR deviation $( \pm 2$ units) which was confirmed by similar levels of $\mathrm{Na} / \mathrm{K}$ consumption within each group. There is clearly a strict metabolic significance to the $\mathrm{Na} / \mathrm{K}$ ratio and its possible influence on the disease course.

The data from our study seem to suggest that the old range of SSPR seems to be too wide. It may, therefore, be necessary to work up a new normal range, testing larger populations of healthy people.

\section{References}

1 Shigeyama Y, Pap T, Kunzler P, et al. Expression of osteoclast differentiation factor in rheumatoid arthritis. Arthritis Rheum 2000;43;2523-30.

2. Redlich K, Hayer S, Maier A, et al. Tumor necrosis factor alpha-mediated joint destruction is inhibited by targeting osteoclasts with osteoprotegerin. Arthritis Rheum 2002;46:785-92.

3. Diarra D, Stolina M, Polzer K, et al. Dickkopf-1 is a master regulator of joint remodeling. Nat Med 2007;13:156-63.

4. Miller JR. The Wnts. Genome Biol 2001;3:3001.1-15.

5. Lu W, Kim KA, Liu J, et al. R-spondin1 syn- ergizes with Wnt3A in inducing osteoblast differentiation and osteoprotegerin expression. FEBS Lett 2008;582:643-50.

6. Inkson CA, Ono M, Kuznetsov SA, et al. TGF-betal and WISP-1/CCN-4 can regulate each other's activity to cooperatively control osteoblast fuction. J Cell Biochem 2008;104:1865-78.

7. Wynn TA. Cellular and molecular mechanisms of fibrosis. J Pathol 2008;214:199210.

8. Willenberg HS, Kolentini C, Quinkler M, et al. The serum sodium to urinary sodium to (serum potassium)2 to urinary potassium (SUSPPUP) ratio in patients with primary aldosteronism. Eur J Clin Invest 2009;39:43-50.

9. Channa NA, Khad F, Ghanghro AB, et al. Comparative Study of Sodium and Potassium in Different Types of Gallstones and in Serum of Subjects with Gallstones and Controls. Pak J Anal Environ Chem 2008;9:38-42.

10. Rovensky J, Kvetnansky R, Radikova Z, et al. Hormone concentrations in synovial fluid of patients with rheumatoid arthritis. Clin Exp Rheumatol 2005;23:292-6.

11. Bendtzen K, Hansen PR, Rieneck K; Spironolactone/Arthritis Study Group. Spironolactone inhibits production of proinflammatory cytokines, including tumor necrosis factor-alpha and interferone-gamma, and has potential in the treatment of arthritis. Clin Exp Immunol 2003;134:151-8.

12. Loeser RF. Aging and osteoarthritis: the role of chondrocyte senescence and aging changes in the cartilage matrix. Osteoarthritis Cartilage 2009 Mar 12. [Epub ahead of print]

13. Hubbard JB, Mattmueller DR, Steinberg $\mathrm{JJ}$, et al. Effect of steroid hormones on endotoxin-mediated cartilage degradation. Mol Cell Biochem 1988;79:31-7. 